\title{
Adult glucose metabolism in extremely birthweight-discordant monozygotic twins
}

\author{
M. Frost • I. Petersen - K. Brixen • H. Beck-Nielsen • \\ J. J. Holst • L. Christiansen • K. Højlund • \\ K. Christensen
}

Received: 12 March 2012 / Accepted: 21 June 2012 /Published online: 7 September 2012

(C) Springer-Verlag 2012

\begin{abstract}
Aims/hypothesis Low birthweight (BW) is associated with increased risk of type 2 diabetes. We compared glucose metabolism in adult BW-discordant monozygotic (MZ) twins, thereby controlling for genetic factors and rearing environment. Methods Among 77,885 twins in the Danish Twin Registry, 155 of the most BW-discordant MZ twin pairs (median BW difference $0.5 \mathrm{~kg}$ ) were assessed using a $2 \mathrm{~h}$ oral glucose tolerance test with sampling of plasma (p-)glucose, insulin, C-peptide, glucose-dependent insulinotropic polypeptide and glucagon-like peptide-1. HOMA for beta cell function
\end{abstract}

Electronic supplementary material The online version of this article (doi:10.1007/s00125-012-2695-x) contains peer-reviewed but unedited supplementary material, which is available to authorised users.

M. Frost $(\bowtie) \cdot$ I. Petersen $\cdot$ L. Christiansen $\cdot$ K. Christensen The Danish Twin Registry, Department of Epidemiology,

University of Southern Denmark,

JB Winsløvsvej 9,

5000 Odense C, Denmark

e-mail: frostnielsen@yahoo.com

M. Frost $\cdot$ K. Brixen $\cdot$ H. Beck-Nielsen $\cdot$ K. Højlund

Department of Endocrinology and Metabolism,

Odense University Hospital,

Odense, Denmark

\section{J. J. Holst}

NovoNordisk Foundation Center for Basic Metabolic Research,

Department of Biomedical Sciences, The Panum Institute,

University of Copenhagen,

Copenhagen, Denmark

\section{K. Christensen}

Department of Clinical Biochemistry and Pharmacology,

Odense University Hospital,

Odense, Denmark

\section{K. Christensen}

Department of Clinical Genetics, Odense University Hospital,

Odense, Denmark
(HOMA- $\beta$ ) and insulin resistance (HOMA-IR), and also insulin sensitivity index (BIGTT-SI) and acute insulin response (BIGTT-AIR), were calculated. Subgroup analyses were performed in those with: (1) double verification of BW difference; (2) difference in BW $>0.5 \mathrm{~kg}$; and (3) no overt metabolic disease (type 2 diabetes, hyperlipidaemia or thyroid disease). Results No intra-pair differences in p-glucose, insulin, $C$-peptide, incretin hormones, HOMA- $\beta$, HOMA-IR or BIGTT-SI were identified. p-Glucose at 120 min was higher in the twins with the highest BW without metabolic disease, and BIGTT-AIR was higher in those with the highest BW although not in pairs with a BW difference of $>0.5 \mathrm{~kg}$. Conclusions/interpretation $\mathrm{BW}$-discordant $\mathrm{MZ}$ twins provide no evidence for a detrimental effect of low BW on glucose metabolism in adulthood once genetic factors and rearing environment are controlled for.

Keywords Birthweight $\cdot$ Fetal programming $\cdot$ Incretin hormones · Oral glucose tolerance test · Twins - Type 2 diabetes

\begin{tabular}{|c|c|}
\hline \multicolumn{2}{|c|}{ Abbreviations } \\
\hline BIGTT-AIR & $\begin{array}{l}\text { OGTT-derived index of acute insulin } \\
\text { response }\end{array}$ \\
\hline BIGTT-SI & OGTT-derived index of insulin sensitivity \\
\hline BW & Birthweight \\
\hline $\mathrm{DZ}$ & Dizygotic \\
\hline GIP & $\begin{array}{l}\text { Glucose-dependent insulinotropic } \\
\text { polypeptide }\end{array}$ \\
\hline GLP-1 & Glucagon-like peptide-1 \\
\hline HOMA- $\beta$ & HOMA of beta cell function \\
\hline HOMA-IR & HOMA of insulin resistance \\
\hline $\mathrm{MZ}$ & Monozygotic \\
\hline p-Glucose & Plasma glucose \\
\hline s-C-peptide & Serum C-peptide \\
\hline s-Insulin & Serum insulin \\
\hline
\end{tabular}




\section{Introduction}

Increased levels of fasting glucose and diabetes are associated with increased morbidity and premature death [1]. In individuals with type 2 diabetes, insulin secretion is insufficient to compensate for the degree of insulin resistance [2]. Studies in twins have shown that type 2 diabetes is in part heritable [3], but factors in early life may also predispose to the development of type 2 diabetes. According to the fetal origin hypothesis, intrauterine malnutrition may predispose to adverse health outcomes in later life, including type 2 diabetes [4], and low birthweight (BW) has been associated with an increased risk of type 2 diabetes suggesting that the susceptibility to the development of type 2 diabetes is established in prenatal life [5]. Support for this hypothesis has been provided by several studies. In rats, maternal undernutrition changed the gene expression profile that predisposes to altered fat deposition [6], whereas signs of increased oxidative stress and fibrosis were discovered in pancreatic islets in offspring of protein-restricted pregnant rats [7]. However, whether the association between early life factors and the development of type 2 diabetes is due to fetal programming or underlining common genetic and environmental influence remains debatable. Twin status was associated with reduced insulin sensitivity and higher incidence rate of type 2 diabetes in a study that comprised 298 twins and 71 singletons, indicating that pre- or postnatal programming influences the development of type 2 diabetes [8]. Since the average BW of a twin is about $1 \mathrm{~kg}$ less than that of a singleton [9], a higher prevalence of diabetes would be expected in twins compared with singletons based on the fetal origin hypothesis. Nevertheless, the prevalence of type 2 diabetes was similar in Swedish twins compared with the general population [10], and type 2 diabetes was equally common in 77,855 monozygotic (MZ) and dizygotic (DZ) twins as in a random sample of 220,000 age- and sex-matched individuals in Denmark [3].

We investigated the association between $\mathrm{BW}$ and indices of glucose metabolism. Since such associations are potentially explained by a number of factors, including fetal programming, genetics and confounding from shared environment, we recruited adult, monozygotic, extremely BWdiscordant twins. If BW is associated with health in later life independently of genes and rearing environment, significant differences in markers of glucose metabolism would be expected in these individuals.

\section{Methods}

Study population The Danish Twin Registry comprised 77,855 twins, including 17,331 MZ twins, in 2010 [11]. Based on information on zygosity and BW, the 379 most
BW-discordant $\mathrm{MZ}$ twin pairs were identified. We aimed to include $150 \mathrm{MZ}$ twin pairs. A total of $336 \mathrm{MZ}$ twin pairs were consecutively invited by mail to participate until at least 150 twin pairs were enrolled.

Zygosity Zygosity of the twins in the Danish Twin Registry had previously been assigned on the basis of physical resemblance, which provided $>95 \%$ accuracy of classification [12], but zygosity of those included in the study was confirmed using 12 highly polymorphic microsatellite markers. Identity in all markers indicated $>0.99$ probability of monozygosity.

Birthweight Information on BW of the twins in the Danish Registry was retrieved from the Danish Birth Record Registry on those born after 1973 (registered 1973-1978 and from 1979 in groups of 250 and $100 \mathrm{~g}$, respectively) and from midwife records on those born before 1973 (reported with varying precision).

Questionnaire Participants filled out a questionnaire on lifestyle factors, pregnancy, medication and comorbidity, including endocrine and metabolic diseases (e.g. type 2 diabetes, hyperlipidaemia and thyroid dysfunction). In addition, participants answered a question about who of the twins was the heavier at birth.

Non-participation Potential participants were excluded if they met one of the exclusion criteria. These included inability to attend clinical evaluation and tests, present or recent ( $<6$ months) pregnancy, and diseases contraindicating an overnight fast (e.g. type 1 diabetes).

Among those invited to participate in the study, 178 twin pairs declined participation due to both twins being too ill to participate $(n=4)$, one twin being too ill $(n=16)$, one or both twins not being willing to participate $(n=74$ and 25 , respectively), no response from one or both of the twins $(n=8)$, or other reasons including low mobility, travel distance etc. $(n=51)$ (Fig. 1).

Furthermore one of the twin pairs was found to be dizygotic, based on genetic testing, and another twin pair disagreed on who had been the heavier at birth; both of these pairs were therefore excluded from further analyses. A third twin pair was excluded when one of the twins became pregnant.

In 22 cases, only one twin had filled out the questionnaire. Subgroup analyses were performed for the double verification group of 133 pairs where both twins filled out the questionnaire and independently agreed on who had been the heavier at birth.

Outcomes The primary outcomes of the study were differences in fasting and glucose levels after an OGTT. Measures 
Fig. 1 Flowchart of the inclusion of study participants

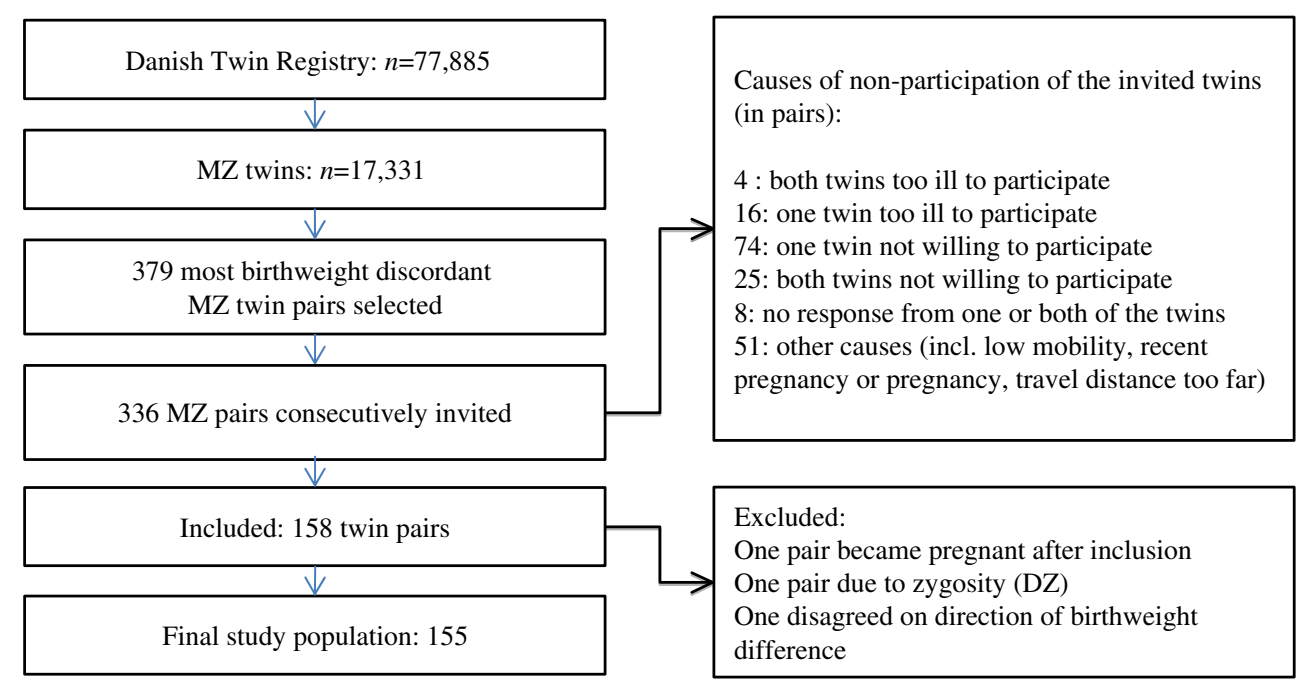

of insulin sensitivity and beta cell function, as well as incretin hormones, were considered secondary, exploratory variables.

Further explorations of these outcomes were conducted in three subgroup analyses. The first subgroup analysis was performed in those with difference in BW exceeding $0.5 \mathrm{~kg}$, to investigate whether differences in glucose metabolism were present only in cases of extreme BW discordancy. Since dissimilarity in BW within twin pairs may originate from causes that are specific to twins (i.e. twin-to-twin transfusion syndrome), analyses were repeated in twin pairs with a smaller BW discordance $(<0.5 \mathrm{~kg})$. Due to the potential risk of incorrect registration of $\mathrm{BW}$ in the public register or birth records, the second subgroup analysis comprised twins who provided self-reported knowledge on BW discordance that verified the information retrieved from the public records. Therefore, this group comprised twins with double verification of BW discordance. The third subgroup analysis was performed in twins without self-reported metabolic diseases in order to reduce effects of these diseases and their treatment on the outcomes of interest.

The study was approved by the Local Ethics Committee (S-20090033) and conducted in accordance with the Helsinki II declaration. Participants consented in writing to participate in the study.

Biochemical tests Samples were collected between 07:00 and 09:00 hours after an overnight fast of at least $8 \mathrm{~h}$. A $2 \mathrm{~h}$ OGTT was performed using $75 \mathrm{~g}$ glucose dissolved in $200 \mathrm{ml}$ water. Blood for glucose, insulin, C-peptide, total glucose-dependent insulinotropic polypeptide (GIP) and glucose-dependent insulinotropic polypeptide (GLP-1) determination was collected at times 0,30 and $120 \mathrm{~min}$ and stored at $-80^{\circ} \mathrm{C}$ until analyses. Plasma (p-)glucose, serum (s-)insulin and s-C-peptide were measured using the glucose oxidase technique and a time-resolved immunofluorometric assay (AutoDELFIA; Wallac, Turku, Finland), respectively.
Total GLP-1 was determined using a radioimmunoassay (antiserum no. 89390) specific for the C-terminal of the GLP-1 molecule as previously described [13]. Total GIP was measured using a C-terminally directed antiserum [13].

Body composition BMI $\left(\mathrm{kg} / \mathrm{m}^{2}\right)$ was calculated as body weight divided by body height ${ }^{2}$.

Statistics Data are reported as mean (SD). The natural logarithm was used to transform skewed data. Results are reported without adjustment for multiple testing.

HOMAs of beta cell function and insulin resistance (HOMA- $\beta$ and HOMA-IR, respectively) were calculated using models presented by Mathews et al [14]. The insulin sensitivity index (BIGTT-SI $0-30-120$ ) and acute insulin response (BIGTT-AIR ${ }_{0-30-120}$ ) were estimated on the basis of the OGTT using algorithms suggested by Hansen and colleagues [15]. The AUCs for glucose, GIP and GLP-1 were calculated using the trapezoidal method.

Two sets of analyses of the BW-glucose metabolism association were performed. First, twins were treated as individuals to test whether the usually observed association between BW and glucose metabolism was present in the sample. Second, intra-pair differences in glucose metabolism were assessed.

The associations between markers of glucose metabolism and BW were assessed using regression analysis, and similar associations were investigated using regression analyses that included age, BMI, sex and metabolic comorbidity (thyroid disease, diabetes and hyperlipidaemia). Stata's cluster option was used to account for possible within-pair correlations that might otherwise underestimate the SE in both analyses.

In the second set of analyses, within MZ twin-pair differences (twin with higher BW vs twin with lower BW) of continuous measures were compared using Student's $t$ test. The $\chi^{2}$ test was used for categorical measures. Three 
subgroup analyses were performed for twin pairs characterised by: (1) difference in $\mathrm{BW}>0.5 \mathrm{~kg}$; (2) double verification of BW and (3) absence of any known metabolic comorbidity. Fixed-effect regression was used to assess the association between measures of glucose metabolism and BW within twin pairs, with or without adjustment for BMI. Within-pair differences of indices of glucose metabolism are presented as scatter plots and regression lines with 95\% CIs.

Calculations were performed using Stata (Stata Corp, College Station, TX, USA).

\section{Results}

The distribution of BWs is presented in Fig. 2. Median age and mean difference in BW were 58 years and $0.5 \mathrm{~kg}$, respectively (Table 1). Thirty-nine participants (13\%) reported thyroid disease, hyperlipidaemia or type 2 diabetes, and $22(56 \%)$ of these participants were from the lowest BW group ( $p>0.1)$.

Those with the higher BW were on average heavier $(3 \mathrm{~kg}$, $p<0.01)$ and taller $(1.8 \mathrm{~cm}, p<0.01)$, while BMI was similar in the two groups. Subgroup analyses provided similar results, although BMI was higher in those with the higher BW who also reported no metabolic comorbidity $\left(0.7 \mathrm{~kg} / \mathrm{m}^{2}, p<0.01\right)$.

Results from the OGTT were available in 148 (95\%) pairs of the study population. Information on OGTT was available in $129(97 \%)$ of the 133 twin pairs with double verification of BW, 118 of those 123 pairs $(96 \%)$ without overt metabolic disease and 44 of those $46(96 \%)$ with a $>0.5 \mathrm{~kg}$ BW difference.

Mean p-glucose $\mathrm{emin}_{0 \text { and }}$ p-glucose ${ }_{120 \mathrm{~min}}$ were $5.7 \mathrm{mmol} / \mathrm{l}$ and $6.5 \mathrm{mmol} / \mathrm{l}$, respectively. Median (interquartile) $\mathrm{s}-$ insulin $_{0 \mathrm{~min}}$ and s-insulin ${ }_{120 \mathrm{~min}}$ were 32 (22-45) and 154 (92-244) pmol/l, respectively, and mean (SD) s-C-peptide ${ }_{0 \text { min }}$ and s-Cpeptide $_{120 \mathrm{~min}}$ were 628 (358) and 2289 (1062) nmol/l, mean (SD) $\mathrm{GIP}_{0 \min }$ and $\mathrm{GIP}_{120 \mathrm{~min}}$ were 5.2 (8.1) and 28.9 (18.7) pmol/l, and mean (SD) GLP-1 $1_{0 \min }$ and GLP-1 120 min were 6.4

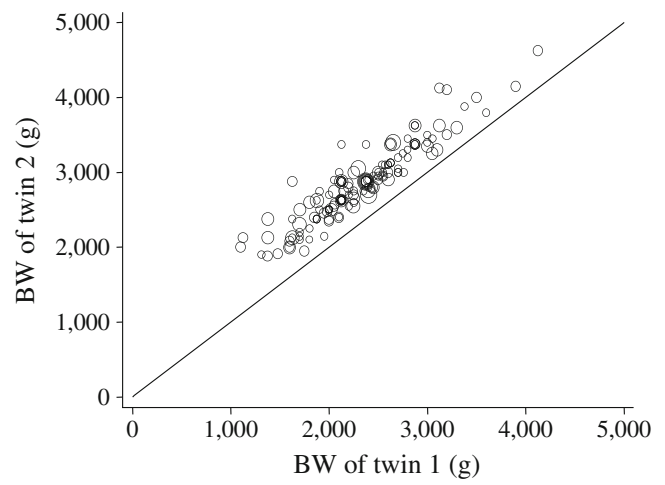

Fig. 2 Distribution of BWs
Table 1 Anthropometrics of the study population

\begin{tabular}{lll}
\hline Characteristic & Women $(n=140)$ & Men $(n=156)$ \\
\hline Age (years) & $58(30-74)$ & $58(30-75)$ \\
BW (kg) & $2.5(2.1-2.8)$ & $2.7(2.3-3.1)$ \\
Length at birth (cm) & $48(46-50)$ & $49(47-51)$ \\
Within-twin-pair BW & $0.5(0.2-1.3)$ & $0.5(0.2-1.3)$ \\
$\quad$ difference (kg), median (range) & & $178 \pm 7$ \\
Height $(\mathrm{cm})$ & $165 \pm 6$ & $83 \pm 13.7$ \\
Weight $(\mathrm{kg})$ & $63 \pm 10.8$ & $26.3 \pm 4.0$ \\
BMI $\left(\mathrm{kg} / \mathrm{m}^{2}\right)$ & $23.2 \pm 4.1$ & \\
\hline
\end{tabular}

Data are presented as median (range) or mean $\pm \mathrm{SD}$

(3.2) and 12.0 (5.9) pmol/l, respectively. In the complete study population, HOMA- $\beta$ was $49.0 \%$, HOMA-IR 1.3 , BIGTTAIR 639.1 and BIGTT-SI 9.3.

Eight individuals had p-glucose ${ }_{120 \mathrm{~min}}$ levels exceeding $\geq 11.1 \mathrm{mmol} / 1$ (i.e. type 2 diabetes), and four of these belonged to those with the highest BW $(p>0.1)$. Forty-one participants had impaired glucose tolerance (p-glucose 7.8$11.1 \mathrm{mmol} / \mathrm{l})$, and $24(59 \%)$ of these were the twin with higher BW $(p>0.1)$. Furthermore, 247 participants had normal glucose tolerance $(<7.8 \mathrm{mmol} / \mathrm{l})$, and $120(49 \%)$ of these were heaviest at birth $(p>0.1)$.

BW was inversely associated with p-glucose ${ }_{120 \text { min }}$ in bivariate $(r-0.75, p<0.01)$ and multivariate regression models $(r-0.71, p<0.01)$. BW was inversely associated with p-glucose $30 \mathrm{~min}$ and $\mathrm{AUC}_{\text {glucose }}$ and directly associated with BIGTT-SI and BIGTT-AIR in multiple regression models. Neither GIP nor GLP1 (fasting as well as AUC) nor any of the HOMA indices were inversely associated with BW (Table 2).

Table 2 Association between BW and measures of glucose metabolism using multiple regression analyses

\begin{tabular}{lllll}
\hline Measure & BW Model A & $p$ & BW Model B & $p$ \\
\hline Glucose $_{0}$ & -0.04 & $>0.1$ & -0.11 & $>0.1$ \\
Glucose $_{30}$ & -0.37 & 0.10 & -0.55 & 0.02 \\
Glucose $_{120}$ & -0.75 & $<0.01$ & -0.71 & $<0.01$ \\
AUC glucose & -57.2 & 0.05 & -67.5 & $<0.01$ \\
AUC GIP & -10.3 & $>0.1$ & 54.8 & $>0.1$ \\
AUC GLP1 & -121.4 & $>0.1$ & 22.1 & $>0.1$ \\
HOMA-IR & -3.5 & 0.05 & -3.1 & 0.08 \\
HOMA- $\beta$ & -7.7 & 0.05 & -5.7 & $>0.1$ \\
BIGTT-SI $^{\mathrm{a}}$ & 0.86 & 0.08 & 1.4 & $<0.01$ \\
BIGTT-AIR $^{\mathrm{a}}$ & 58.7 & 0.04 & 60.6 & 0.03 \\
\hline
\end{tabular}

Results are shown as regression coefficients $(r)$

${ }^{\text {a }}$ Not adjusted for BMI since BMI is included in the algorithm

Model A, adjusted for cluster effect; Model B, adjusted for age, sex, BMI, prevalent metabolic comorbidity and cluster effect 
The comparison of p-glucose in twins with the higher and lower intra-pair BW is presented in Table 3. The within-pair differences in p-glucose $\mathrm{e}_{0 \text { min }}$ and p-glucose $\mathrm{e}_{120 \min }$ were not statistically significant, but p-glucose $1_{120 \mathrm{~min}}$ was higher in those with the higher BW in the subgroup analysis that included individuals without any overt metabolic comorbidity.

Neither fasting nor post-OGTT p-glucose levels differed significantly between twin pairs with less than $0.5 \mathrm{~kg}$ difference in BW. $\mathrm{p}$-Glucose $\mathrm{e}_{0 \mathrm{~min}}$ and p-glucose ${ }_{120 \mathrm{~min}}$ differed (twin with higher BW vs twin with lower BW) by $0.1 \mathrm{mmol} / \mathrm{l}$ and $0.7 \mathrm{mmol} / \mathrm{l}$ (both $p>0.1$ ), respectively.

Both before and by the end of the OGTT, s-insulin and s-C-peptide were similar in those with higher compared with lower BW. Neither pre- nor post-OGTT GIP differed between the BW-discordant twins. Baseline but not postOGTT GLP1 was higher in those with the lower BW and double verification of BW difference; however, no difference was found after stratification according to a difference in $\mathrm{BW}$ of at least $0.5 \mathrm{~kg}$ (Table 3).

HOMA- $\beta$ as well as HOMA-IR and BIGTT-SI were similar in those with high and low BW. BIGTT-AIR was higher in the twin with the higher BW in the complete study population as well as in those without overt metabolic disease. However, BIGTT-AIR was not statistically different in those with the largest difference in BW (Table 4). AUC was calculated for p-glucose, GIP and GLP-1. None of these measures differed between those with the higher and the lower BW of the twin pair (Table 4).

Within-pair differences in indices of glucose metabolism are presented graphically (see electronic supplementary material [ESM] Fig. 1). None of the slopes, except that for BIGTT-AIR, were different from zero.

Intra-pair differences in BW were not associated with fasting or post-OGTT p-glucose levels in fixed-effect regression analyses, and inclusion of BMI in the models did not change the results (ESM Table 1).

\section{Discussion}

The main findings of this study were similar levels of $p$ glucose before and after a $2 \mathrm{~h}$ glucose tolerance test in a large sample of MZ twins characterised by extreme BW discordance. Subgroup analyses performed in those with the largest difference in BW, double verification of $\mathrm{BW}$, and absence of overt metabolic disease did not suggest any

Table 3 Comparison of glucose, insulin, C-peptide and incretin hormones in BW-discordant MZ twins during a 2 h OGTT

\begin{tabular}{|c|c|c|c|c|c|c|c|c|}
\hline \multirow[t]{2}{*}{ Measure } & \multicolumn{2}{|c|}{$\begin{array}{l}\text { MZ pairs with complete data } \\
\text { on OGTT ( } n=148 \text { pairs })\end{array}$} & \multicolumn{2}{|c|}{$\begin{array}{l}\text { MZ pairs with BW difference } \\
\text { of }>0.5 \mathrm{~kg}(n=44)\end{array}$} & \multicolumn{2}{|c|}{$\begin{array}{l}\text { Pairs with double verification } \\
\text { of BW discordance }(n=129)\end{array}$} & \multicolumn{2}{|c|}{$\begin{array}{l}\text { Pairs without overt metabolic } \\
\text { disease }(n=118)\end{array}$} \\
\hline & $\begin{array}{l}\text { Difference, } \\
\text { mean } \pm \text { SD or median } \\
\text { (interquartile range) }\end{array}$ & $p$ & $\begin{array}{l}\text { Difference, } \\
\text { mean } \pm \mathrm{SD} \text { or median } \\
\text { (interquartile range) }\end{array}$ & $p$ & $\begin{array}{l}\text { Difference, mean } \pm \text { SD } \\
\text { or median } \\
\text { (interquartile range) }\end{array}$ & $p$ & $\begin{array}{l}\text { Difference, mean } \pm \text { SD } \\
\text { or median } \\
\text { (interquartile range) }\end{array}$ & $p$ \\
\hline Height (m) & $1.75 \pm 2.6$ & $<0.01$ & $1.85 \pm 2.4$ & $<0.01$ & $1.85 \pm 2.4$ & $<0.01$ & $1.81 \pm 2.6$ & $<0.01$ \\
\hline Weight (kg) & $2.9 \pm 10.1$ & $<0.01$ & $2.9 \pm 10.3$ & $<0.01$ & $2.9 \pm 10.3$ & $<0.01$ & $3.6 \pm 9.8$ & $<0.01$ \\
\hline BMI $\left(\mathrm{kg} / \mathrm{m}^{2}\right)$ & $0.4 \pm 3.4$ & $>0.1$ & $0.4 \pm 3.5$ & $>0.1$ & $0.4 \pm 3.5$ & $>0.1$ & $0.7 \pm 3.2$ & 0.03 \\
\hline Glucose $_{0}(\mathrm{mmol} / \mathrm{l})$ & $0.04 \pm 0.57$ & $>0.1$ & $-0.03 \pm 0.45$ & $>0.1$ & $0.03 \pm 0.59$ & $>0.1$ & $0.06 \pm 0.57$ & $>0.1$ \\
\hline Glucose $_{30}(\mathrm{mmol} / \mathrm{l})$ & $-0.07 \pm 1.72$ & $>0.1$ & $-0.31 \pm 1.50$ & $>0.1$ & $0.00 \pm 1.76$ & $>0.1$ & $-0.07 \pm 1.71$ & $>0.1$ \\
\hline Glucose $_{120}(\mathrm{mmol} / \mathrm{l})$ & $0.23 \pm 2.02$ & $>0.1$ & $-0.04 \pm 2.31$ & $>0.1$ & $0.26 \pm 2.09$ & $>0.1$ & $0.43 \pm 2.0$ & 0.02 \\
\hline Insulin $_{0}(\mathrm{pmol} / \mathrm{l})$ & $0(-12,14)$ & $>0.1^{\mathrm{a}}$ & $-1(-9,12)$ & $>0.1^{\mathrm{a}}$ & $0(-9,13)$ & $>0.1^{\mathrm{a}}$ & $0(-9,13)$ & $>0.1^{\mathrm{a}}$ \\
\hline Insulin $_{30}(\mathrm{pmol} / \mathrm{l})$ & $-11(-130,61)$ & $>0.1^{\mathrm{a}}$ & $27(-78,138)$ & $>0.1^{\mathrm{a}}$ & $-3(-130,61)$ & $>0.1^{\mathrm{a}}$ & $0(-124,67)$ & $>0.1^{\mathrm{a}}$ \\
\hline Insulin $_{120}(\mathrm{pmol} / \mathrm{l})$ & $15(-77,76)$ & $>0.1^{\mathrm{a}}$ & $21(-50,71)$ & $>0.1^{\mathrm{a}}$ & $15(-67,76)$ & $>0.1^{\mathrm{a}}$ & $19(-54,77)$ & $>0.1^{\mathrm{a}}$ \\
\hline C-peptide ${ }_{0}(\mathrm{nmol} / \mathrm{l})$ & $29.1 \pm 364.6$ & $>0.1$ & $-5.9 \pm 322.3$ & $>0.1$ & $31.0 \pm 384.3$ & $>0.1$ & $39.7 \pm 271.8$ & $>0.1$ \\
\hline C-peptide $30(\mathrm{nmol} / \mathrm{l})$ & $-69.8 \pm 841.2$ & $>0.1$ & $72.8 \pm 615.1$ & $>0.1$ & $-51.5 \pm 835.8$ & $>0.1$ & $-14.3 \pm 785.2$ & $>0.1$ \\
\hline C-peptide ${ }_{120}(\mathrm{nmol} / \mathrm{l})$ & $83 \pm 1036$ & $>0.1$ & $124 \pm 1010$ & $>0.1$ & $79 \pm 1065$ & $>0.1$ & $128 \pm 1021$ & $>0.1$ \\
\hline $\mathrm{GIP}_{0}(\mathrm{pmol} / \mathrm{l})$ & $0.06 \pm 12.5$ & $>0.1$ & $0.4 \pm 17.0$ & $>0.1$ & $0.7 \pm 12.6$ & $>0.1$ & $0.1 \pm 9.7$ & $>0.1$ \\
\hline $\mathrm{GIP}_{30}(\mathrm{pmol} / \mathrm{l})$ & $-0.04 \pm 18.3$ & $>0.1$ & $-0.1 \pm 18.2$ & $>0.1$ & $-0.4 \pm 18.8$ & $>0.1$ & $0.7 \pm 16.4$ & $>0.1$ \\
\hline $\mathrm{GIP}_{120}(\mathrm{pmol} / \mathrm{l})$ & $-0.31 \pm 21.3$ & $>0.1$ & $-1.9 \pm 23.4$ & $>0.1$ & $-0.7 \pm 21.8$ & $>0.1$ & $-0.7 \pm 19.5$ & $>0.1$ \\
\hline $\mathrm{GLP}_{0}(\mathrm{pmol} / \mathrm{l})$ & $-0.50 \pm 3.14$ & 0.06 & $-0.5 \pm 3.1$ & $>0.1$ & $-0.6 \pm 3.2$ & 0.04 & $-0.5 \pm 2.9$ & 0.07 \\
\hline $\mathrm{GLP}_{30}(\mathrm{pmol} / \mathrm{l})$ & $0.63 \pm 11.3$ & $>0.1$ & $1.6 \pm 8.1$ & $>0.1$ & $1.0 \pm 11.1$ & $>0.1$ & $0.9 \pm 10.1$ & $>0.1$ \\
\hline $\mathrm{GLP}_{120}(\mathrm{pmol} / \mathrm{l})$ & $-0.57 \pm 6.64$ & $>0.1$ & $-0.5 \pm 6.7$ & $>0.1$ & $0.8 \pm 6.9$ & $>0.1$ & $-0.7 \pm 6.8$ & $>0.1$ \\
\hline
\end{tabular}

Individuals with highest BW were compared with those with lowest BW using Student's $t$ test

${ }^{\text {a }}$ Statistical test after log-transformation 
Table 4 Comparison of indices of glucose metabolism calculated on the basis of a $2 \mathrm{~h}$ OGTT in BW-discordant MZ twins

\begin{tabular}{|c|c|c|c|c|c|c|c|c|}
\hline \multirow[t]{2}{*}{ Measure } & \multicolumn{2}{|c|}{$\begin{array}{l}\text { MZ pairs with complete data } \\
\text { on OGTT ( } n=148 \text { pairs) }\end{array}$} & \multicolumn{2}{|c|}{$\begin{array}{l}\text { MZ pairs with BW difference } \\
\text { of }>0.5 \mathrm{~kg}(n=44)\end{array}$} & \multicolumn{2}{|c|}{$\begin{array}{l}\text { Pairs with double verification } \\
\text { of BW discordance } \\
(n=129)\end{array}$} & \multicolumn{2}{|c|}{$\begin{array}{l}\text { Pairs without metabolic } \\
\text { disease }(n=118)\end{array}$} \\
\hline & $\begin{array}{l}\text { Difference, } \\
\text { mean } \pm \mathrm{SD} \text { or median } \\
\text { (interquartile range) }\end{array}$ & $p$ & $\begin{array}{l}\text { Difference, } \\
\text { mean } \pm \text { SD or median } \\
\text { (interquartile range) }\end{array}$ & $p$ & $\begin{array}{l}\text { Difference, } \\
\text { mean } \pm \text { SD or median } \\
\text { (interquartile range) }\end{array}$ & $p$ & $\begin{array}{l}\text { Difference, } \\
\text { mean } \pm \text { SD or median } \\
\text { (interquartile range) }\end{array}$ & $p$ \\
\hline HOMA- $\beta^{\mathrm{a}}$ & $0.0(-16.1,17.6)$ & $>0.1$ & $-0.1(-10.9,17.0)$ & $>0.1$ & $0.0(-18.6,18.9)$ & $>0.1$ & $0.0(-17.0,17.9)$ & $>0.1$ \\
\hline HOMA-IR ${ }^{\mathrm{a}}$ & $-0.02(-0.5,0.6)$ & $>0.1$ & $-0.06(-4.3,7.3)$ & $>0.1$ & $0.0(-0.4,0.5)$ & $>0.1$ & $-0.01(-0.4,0.5)$ & $>0.1$ \\
\hline BIGTT- $\mathrm{SI}_{0-30-120}$ & $-0.2 \pm 3.5$ & $>0.1$ & $-0.2 \pm 3.4$ & $>0.1$ & $-0.2 \pm 3.6$ & $>0.1$ & $-0.3 \pm 3.4$ & $>0.1$ \\
\hline BIGTT-AIR $_{0-30-120}$ & $50.6 \pm 268.8$ & 0.03 & $9.7 \pm 233.7$ & $>0.1$ & $44.8 \pm 267.2$ & 0.08 & $64.5 \pm 271.0$ & 0.01 \\
\hline $\mathrm{AUC}_{\text {glucose }}(\mathrm{mmol} / \mathrm{l} \times \mathrm{h})$ & $6.4 \pm 168.0$ & $>0.1$ & $21.0 \pm 164.0$ & $>0.1$ & $11.8 \pm 173.0$ & $>0.1$ & $15.8 \pm 164.9$ & $>0.1$ \\
\hline $\mathrm{AUC}_{\mathrm{GLP} 1}(\mathrm{pmol} / \mathrm{l} \times \mathrm{h})$ & $-17.0 \pm 832.4$ & $>0.1$ & $61.4 \pm 666.9$ & $>0.1$ & $-8.9 \pm 820.6$ & $>0.1$ & $-9.7 \pm 747.6$ & $>0.1$ \\
\hline $\mathrm{AUC}_{\mathrm{GIP}}(\mathrm{pmol} / 1 \times \mathrm{h})$ & $-46.5 \pm 1941.1$ & $>0.1$ & $-104.0 \pm 2145.2$ & $>0.1$ & $-82.0 \pm 1997.5$ & $>0.1$ & $-15.4 \pm 1707.6$ & $>0.1$ \\
\hline
\end{tabular}

Twins with the higher BW were compared with the twins with the lower BW using Student's $t$ test

${ }^{\text {a }}$ Statistical test after log-transformation

impact of BW on glucose metabolism in later life. BW and p-glucose levels after OGTT were inversely associated in the twin population in the present study; however, the absence of differences within the pairs in glucose metabolism in BW-discordant MZ twins is in contrast to the fetal origin hypothesis. Rather, our results support the notion that the association between BW and glucose metabolism in later life is due to genetic and rearing/environmental confounding.

In contrast to the fetal origin hypothesis, the subgroup analysis that included participants without overt metabolic disease showed that glucose levels were higher in the twin with the higher BW after the glucose-stress test. However, the overall proportion of individuals with inappropriate levels of glucose after the OGTT was similar in both groups suggesting that the observation is a chance finding rather than an indication of a detrimental effect of high BW on glucose metabolism in adulthood. Furthermore, the acute insulin response appeared to be higher in those with the higher BW. Since impaired insulin secretion has been shown to predict development of type 2 diabetes [16], this could indicate that low BW impairs one of the key elements of the pathogenesis of type 2 diabetes. However, no support for any impact of BW on beta cell function, or indeed basal hepatic glucose production, was provided by the HOMA- $\beta$, and the higher acute insulin response was not present in those twins born with the largest difference in BW. While the OGTT is useful for the detection of individuals with type 2 diabetes or impaired glucose tolerance, the ability of a $2 \mathrm{~h}$ OGTT to predict the development of type 2 diabetes is limited [17]. Taken together, the results based on fasting glucose and OGTT neither support beneficial nor detrimental impacts of BW on current glucose levels or acute insulin responses in adulthood.
Both GIP and GLP-1 are important, since these hormones explain an extensive part of the postprandial amplification of insulin secretion (i.e. the incretin effect [18]). Impairment of the incretin effect is an early and specific sign of inadequate glucose metabolism [19] and, hypothetically, levels of these hormones could be lower in individuals predisposed to type 2 diabetes due to low BW. Although the level of fasting GLP-1 was higher in the twin with the lower BW, levels of GIP and GLP-1 were similar in those with higher and lower $\mathrm{BW}$ during and after a $2 \mathrm{~h}$ OGTT, suggesting that $\mathrm{BW}$ is not associated with the levels of incretin hormones measured in later life.

Barker hypothesised that the association between BW-a proxy for intrauterine conditions-is explained by adaptation of bodily functions conferred by environmental changes at crucial stages of fetal growth [4]. Several studies support the notion. Poulsen and colleagues $[20,21]$ reported lower BW in twins with abnormal glucose tolerance than in twins with normal glucose tolerance. The same investigators also compared levels of p-glucose and insulin in MZ and DZ twins during an OGTT and reported substantially larger differences than expected on the basis of the genetic dissimilarity, suggesting that the unfavourable intrauterine conditions in MZ pregnancies influence glucose metabolism in later life. Using euglycaemic-hyperinsulinaemic clamps, further substantiation was provided by demonstration of lower insulin action in MZ compared with DZ twins [22]. In a study comprising 50 twins and 20 singletons, Jeffries and colleagues [23] demonstrated that twins are at higher risk of developing metabolic abnormalities, whereas Bo and colleagues [24] showed that in twins, within-pair differences in BW were associated with an unfavourable response to OGTT. Conversely, BW was neither a predictor of adult glucose tolerance in $58 \mathrm{MZ}$ twins from the Birmingham 
Twin Study [25] nor associated with insulin resistance in a study comprising more than 1,000 female twins [26]. Moreover, Johansson and colleagues [10] reported that low BW and type 2 diabetes were associated in a population-based study comprising more than 11,000 Swedish twins. Interestingly, the same investigators showed that among twins discordant for type 2 diabetes, low BW was associated with type 2 diabetes in $\mathrm{DZ}$ but not $\mathrm{MZ}$ twins, indicating that genetic factors contribute significantly to the observed association between BW and risk of type 2 diabetes [10]. In addition, although the BW of twins is generally lower than that of singletons, the prevalence of type 2 diabetes in twins is analogous to that observed in the background population $[3,10]$. These previous studies have provided diverse results on the association between BW and type 2 diabetes, which may be explained by differences in study design and, in particular, varying power.

Owing to the importance of genetics and environment on both fetal growth and adult health, it is challenging to investigate the interaction between early life factors (i.e. $\mathrm{BW}$ ) and adverse health consequences in adulthood in singletons. However, comparing $\mathrm{MZ}$ twins discordant for BW makes it possible to control for a number of important confounders including most notably genetics, maternal age, parity, gestational age, and, to some extent, postnatal environment. Although this study was conducted among highly selected MZ twins and one may dispute whether our observations are relevant to other twins and in particular singletons, the discordant twin model provides a superior opportunity to study the independent effects of BW on adult health.

Certain twin-specific conditions may impair the growth of one twin while favouring the growth of the other (e.g. placental anastomosis) causing the twins to become BW discordant. While zygosity appears not to be a major predictor of adverse perinatal outcomes, monochorionicity is associated with unfavourable health-related consequences in perinatal life [27-29]. Information on chorionicity was unavailable in our study population, but we were able to assess glucose metabolism in both the largest and smallest twins. Even though twin pairs with substantial BW discordance were more likely to be monochorionic, these analyses did not indicate any difference in adult glucose metabolism. Nevertheless, the long-term consequences of chorionicity are not clear, and Loos and colleagues reported that the chorion type of $\mathrm{MZ}$ twins had no impact on adult anthropometrics including fat distribution [30]. Furthermore, even dramatic differences in weight in $\mathrm{MZ}$ twins at birth tend to disappear during childhood [31], suggesting that the divergence is not causing extensive and permanent physical changes that render comparison with other individuals unreasonable. In addition, the mortality rate in $\mathrm{MZ}$ twins after the age of 6 years is similar to that in DZ twins and singletons[32], implying that zygosity and chorionicity are unlikely to be of major importance in the assessment of effects of BW on adult health.

Although factors in early postnatal life may have been similar, non-shared postnatal experiences, unaccounted for in the present study, may have influenced important aspects of health in adulthood, including glucose metabolism. Nevertheless, if BW had a substantial effect on glucose metabolism that was independent of genetic and rearing environment, differences in the prevalence of diabetes, inappropriate response to glucose loading or levels of fasting p-glucose would have been expected in the present study.

Although we found no differences in glucose metabolism between $\mathrm{BW}$-discordant $\mathrm{MZ}$ twins, we cannot reject the possibility that low BW influences health in later life. It has been suggested that genetic variations may change the levels of insulin in utero and increase the risk of diabetes in later life [33]. Studies have provided evidence of a genetic explanation for the association between BW and risk of diabetes, and genetic mutations known to cause monogenic forms of diabetes may result in reduced $\mathrm{BW}[33,34]$. Furthermore, fetal inheritance of type 2 diabetes susceptibility variants has been associated with lower BW [35]. Therefore, genetics seem to contribute significantly to the association between BW and health in later life.

The present study has weaknesses. First, we assessed the glucose metabolism using the OGTT, which is associated with substantial intra- and intervariability [36, 37], although OGTT, HOMA, and BIGTT have been shown to provide reliable estimates of insulin sensitivity and beta cell function [15]. Second, the incretin response may have been different if the study participants had received a meal test rather than an OGTT. Third, recruiting extremely BW-discordant MZ twins could contribute bias towards an association between low BW and health due to higher frequency of underlying disease among the low-BW participants. Fourth, measurement error in the exposure (i.e. BW) is a critical factor in within-twin-pair comparisons. Reassuringly, virtually all participants reporting whether they were born at the higher or the lower BW were in agreement (>99\%). Fifth, information about BW was not available in all MZ twin pairs in the Danish Twin Registry, which may explain the low level of BW discordance observed in some of the participants. This is, however, unlikely to interfere with the results of the study since no indication of an independent effect of BW on glucose metabolism was identified in the subgroup consisting of twin pairs with a large difference in BW.

In conclusion, our results do not support any major impact of intrauterine factors, as mirrored by $\mathrm{BW}$, on glucose homeostasis in adulthood once genetic and environmental factors are controlled for. These observations are in concord with previous large register-based studies showing similar prevalence of diabetes in twins and singletons. 
Acknowledgements The authors are grateful to M. Snorgaard and F. Boedker from the Danish Twin Registry for their assistance in the recruitment of study participants and study management.

Funding The study was supported by, and carried out within, the EU-funded Network of Excellence LifeSpan (FP6 036894). The Danish Twin Registry is supported by a grant from The National Program for Research Infrastructure 2007 from the Danish Agency for Science Technology and Innovation. The Danish Aging Research Center is supported by the VELUX Foundation.

Duality of interest The authors declare that there is no duality of interest associated with this manuscript. The funders had no role in study design, data collection and analysis, decision to publish, or preparation of the manuscript.

Contribution statement MF participated in study design, data collection, analyses, drafting of the manuscript, and approved the draft. IP provided statistical advice, helped revise the manuscript, and approved the revised manuscript. $\mathrm{KB}, \mathrm{HBN}$ and $\mathrm{JJH}$ participated in analyses, helped revise the manuscript, and approved the manuscript. LC and KH participated in study design, data collection, helped revise the manuscript, and approved the manuscript. $\mathrm{KC}$ was the principal investigator, participated in study design, supervised the study, helped revise the manuscript, and approved the manuscript.

\section{References}

1. Seshasai SR, Kaptoge S, Thompson A et al (2011) Diabetes mellitus, fasting glucose, and risk of cause-specific death. $\mathrm{N}$ Eng J Med 364:829-841

2. Stumvoll M, Goldstein BJ, van Haeften TW (2008) Type 2 diabetes: pathogenesis and treatment. Lancet 371:2153-2156

3. Petersen I, Nielsen MM, Beck-Nielsen H, Christensen K (2011) No evidence of a higher 10 year period prevalence of diabetes among 77,885 twins compared with 215,264 singletons from the Danish birth cohorts 1910-1989. Diabetologia 54:2016-2024

4. Barker DJP (1998) Mothers, babies, and health in later life. Churchill Livingstone, Edinburgh

5. Whincup PH, Kaye SJ, Owen CG et al (2008) Birth weight and risk of type 2 diabetes: a systematic review. JAMA 300:2886-2897

6. Lukaszewski MA, Mayeur S, Fajardy I et al (2011) Maternal prenatal undernutrition programs adipose tissue gene expression in adult male rat offspring under high-fat diet. Am J Physiol Endocrinol Metab 301:E548-E559

7. Tarry-Adkins JL, Chen JH, Jones RH, Smith NH, Ozanne SE (2010) Poor maternal nutrition leads to alterations in oxidative stress, antioxidant defense capacity, and markers of fibrosis in rat islets: potential underlying mechanisms for development of the diabetic phenotype in later life. FASEB J 24:2762-2771

8. Poulsen P, Grunnet LG, Pilgaard K et al (2009) Increased risk of type 2 diabetes in elderly twins. Diabetes 58:1350-1355

9. Liu YC, Blair EM (2002) Predicted birthweight for singletons and twins. Twin Res 5:529-537

10. Johansson S, Iliadou A, Bergvall N et al (2008) The association between low birth weight and type 2 diabetes: contribution of genetic factors. Epidemiology 19:659-665

11. Skytthe A, Kyvik KO, Holm NV, Christensen K (2011) The Danish Twin Registry. Scand J Public Health 39:75-78

12. Christiansen L, Frederiksen H, Schousboe K et al (2003) Age- and sex-differences in the validity of questionnaire-based zygosity in twins. Twin Res 6:275-278
13. Deacon CF, Nauck MA, Meier J, Hucking K, Holst JJ (2000) Degradation of endogenous and exogenous gastric inhibitory polypeptide in healthy and in type 2 diabetic subjects as revealed using a new assay for the intact peptide. J Clin Endocrinol Metab 85:3575-3581

14. Matthews DR, Hosker JP, Rudenski AS et al (1985) Homeostasis model assessment: insulin resistance and beta-cell function from fasting plasma glucose and insulin concentrations in man. Diabetologia 28: 412-419

15. Hansen T, Drivsholm T, Urhammer SA et al (2007) The BIGTT test: a novel test for simultaneous measurement of pancreatic betacell function, insulin sensitivity, and glucose tolerance. Diabetes Care 30:257-262

16. Weyer C, Bogardus C, Mott DM, Pratley RE (1999) The natural history of insulin secretory dysfunction and insulin resistance in the pathogenesis of type 2 diabetes mellitus. J Clin Invest 104:787-794

17. Bartoli E, Fra GP, Carnevale Schianca GP (2011) The oral glucose tolerance test (OGTT) revisited. Eur J Intern Med 22:8-12

18. Holst JJ, Gromada J (2004) Role of incretin hormones in the regulation of insulin secretion in diabetic and nondiabetic humans. Am J Physiol Endocrinol Metab 287:E199-E206

19. Holst JJ, Knop FK, Vilsboll T, Krarup T, Madsbad S (2011) Loss of incretin effect is a specific, important, and early characteristic of type 2 diabetes. Diabetes Care 34(Suppl 2): S251-S257

20. Poulsen P, Vaag AA, Kyvik KO, Moller Jensen D, Beck-Nielsen H (1997) Low birth weight is associated with NIDDM in discordant monozygotic and dizygotic twin pairs. Diabetologia 40:439-446

21. Poulsen P, Vaag A, Beck-Nielsen H (1999) Does zygosity influence the metabolic profile of twins? A population based cross sectional study. BMJ 319:151-154

22. Poulsen P, Vaag A (2006) The intrauterine environment as reflected by birth size and twin and zygosity status influences insulin action and intracellular glucose metabolism in an ageor time-dependent manner. Diabetes 55:1819-1825

23. Jefferies CA, Hofman PL, Knoblauch H et al (2004) Insulin resistance in healthy prepubertal twins. J Pediatr 144:608-613

24. Bo S, Cavallo-Perin P, Scaglione L, Ciccone G, Pagano G (2000) Low birthweight and metabolic abnormalities in twins with increased susceptibility to Type 2 diabetes mellitus. Diabet Med $17: 365-370$

25. Baird J, Osmond C, MacGregor A et al (2001) Testing the fetal origins hypothesis in twins: the Birmingham twin study. Diabetologia 44:33-39

26. Skidmore PM, Cassidy A, Swaminathan R et al (2008) Relation of birth weight, body mass index, and change in size from birth to adulthood to insulin resistance in a female twin cohort. J Clin Endocrinol Metab 93:516-520

27. Dube J, Dodds L, Armson BA (2002) Does chorionicity or zygosity predict adverse perinatal outcomes in twins? Am J Obstet Gynecol 186:579-583

28. Carroll SG, Tyfield L, Reeve L et al (2005) Is zygosity or chorionicity the main determinant of fetal outcome in twin pregnancies? Am J Obstet Gynecol 193:757-761

29. Hack KE, Derks JB, Elias SG et al (2008) Increased perinatal mortality and morbidity in monochorionic versus dichorionic twin pregnancies: clinical implications of a large Dutch cohort study. BJOG 115:58-67

30. Loos RJ, Beunen G, Fagard R, Derom C, Vlietinck R (2001) The influence of zygosity and chorion type on fat distribution in young adult twins consequences for twin studies. Twin Res 4:356-364

31. Wilson RS (1979) Twin growth: initial deficit, recovery, and trends in concordance from birth to nine years. Ann Hum Biol 6:205-220 
32. Christensen K, Vaupel JW, Holm NV, Yashin AI (1995) Mortality among twins after age 6: fetal origins hypothesis versus twin method. BMJ 310:432-436

33. Hattersley AT, Tooke JE (1999) The fetal insulin hypothesis: an alternative explanation of the association of low birthweight with diabetes and vascular disease. Lancet 353:17891792

34. Pearson ER, Boj SF, Steele AM et al (2007) Macrosomia and hyperinsulinaemic hypoglycaemia in patients with heterozygous mutations in the HNF4A gene. PLoS Med 4:e118
35. Freathy RM, Mook-Kanamori DO, Sovio U et al (2010) Variants in ADCY 5 and near CCNL1 are associated with fetal growth and birth weight. Nat Genet 42:430-435

36. Feskens EJ, Bowles CH, Kromhout D (1991) Intra- and interindividual variability of glucose tolerance in an elderly population. J Clin Epidemiol 44:947-953

37. Schousboe K, Henriksen JE, Kyvik KO, Sorensen TI, Hyltoft Petersen P (2002) Reproducibility of S-insulin and B-glucose responses in two identical oral glucose tolerance tests. Scand J Clin Lab Invest 62:623-630 